\title{
Treatment Options for Carbapenem-Resistant Gram-Negative Infections
}

by Dr. med. Moritz Fritzenwanker, Dr. med. Can Imirzalioglu, Prof. Dr. med. Susanne Herold, Prof. Dr. med. Florian M. Wagenlehner, Prof. Dr. med. Klaus-Peter Zimmer, and Prof. Dr. rer. nat. Trinad Chakraborty

in issue $20-21 / 2018$

\section{Oral Fosfomycin-Supplemental Information Necessary}

This review gives general therapy recommendations, including for oral fosfomycin, for which it lists heart failure as one of the dangerous adverse reactions of the active substance (1). As they stand, these points are ambiguous, to say the least, and require clarification. Table 1 of the review lists oral fosfomycin. However, the oral delivery form of the substance is only approved for the treatment of uncomplicated urinary tract infections (2). Infection by $3 / 4$ multiresistant Gram-negative (MRGN) pathogens are not considered to be straightforward, and oral fosfomycin is inappropriate for treating systemic infections due to its poor absorption and its resulting low levels in tissues. In contrast, intravenous fosfomycin achieves high therapeutic levels and, according to the current S2k guideline of the Paul Ehrlich Society for Chemotherapy, represents an important therapeutic option in the combination therapy of $3 / 4 \mathrm{MRGN}$, especially in intensive care (3). However, it is not listed by the authors in the treatment recommendations given in Table 2. Thus, a relevant therapy option remains hidden. Listing heart failure in the text as a dangerous adverse event of the drug is also misleading. Heart failure as a direct adverse event of fosfomycin is not documented either in the summary of product characteristics or in current reviews on drug safety (4). In summary, the authors unfortunately

\section{In Reply:}

We are grateful for the correspondence and are of course happy to address controversial or unclear issues.

We are likewise convinced that intravenous fosfomycin is an important antibiotic against 3/4 MRGN pathogens, and we use it regularly. For this reason, we listed it several times in Table 1, Table 2, in the article text, and in the Key Messages. Table 2-as stated in the N.B.- - is to be considered as a series of therapy proposals (1). It makes sense to decide which antibiotic scheme should be used based on interdisciplinary discussions about patient- and pathogen-specifics for individual cases.

Therapy recommendations initially refer to carbapenemresistant pathogens without a description of the severity of infection. From these options (and possibly others, based on specific considerations of the patient with reference especially to the infection focus and relevant contraindications), a therapy concept can be selected individually, whereby a patient with sepsis should generally receive intravenous treatment.

In Table 1, we explicitly referred to uncomplicated lower urinary tract infections for oral fosfomycin. We have authorized a correction of the article to clarify that oral fosfomycin is generally only approved for uncomplicated lower urinary tract infections. Whether or not oral fosfomycin is an option in complicated did not adequately differentiate between the different areas of use for oral and intravenous administration of fosfomycin. Only intravenous fosfomycin should be listed as a treatment option for 3/4 MRGN infections.

DOI: 10.3238/arztebl.2019.0115a

\section{References}

1. Fritzenwanker M, Imirzalioglu C, Herold S, Wagenlehner FM, Zimmer KP, ChakrabortyT: Treatment options for carbapenem-resistant gram-negative infections. Dtsch Arztebl Int 2018; 115: 345-52.

2. Fachinformation: Monuril $3000 \mathrm{mg}$ Granulat. www.gelbe-liste.de/produkte/Mon uril-3000-mg-Granulat_113265/fachinformation (last accessed on 2 Januar 2019).

3. Bodmann KF, Grabein B et al.: S2k-Leitlinie der PEG, kalkulierte parenterale Initialtherapie bakterieller Erkrankungen bei Erwachsenen - Update 2018. www.awmf.org/ leitlinien/detail//l/082-006.html (last accessed on 28 Januar 2019).

4. larikov D, Wassel R, Farley J, Nambiar S. Adverse events associated with fosfomycin use: Review of the literature and analyses of the FDA adverse event reporting system database. Infect Dis Ther 2015; 4: 433-58.

\section{Dr. med. Klaus-Friedrich Bodmann}

Klinik für internistische Intensivmedizin und klinische Infektiologie, Eberswalde, Germany

kf.bodmann@klinikum-barnim.de

\section{Conflict of interest statement}

The author has been reimbursed for conference fees and travel expenses, and has received speaking honoraria, from Basilea, Correvio, Accelerate, Infecto-Pharm, Pfizer MSD, and Abbott.

urinary tract infections should be tested in RCTs. However, if it is the only antibiotic with susceptibility, we certainly see it as an option to be discussed-provided that no better alternatives are available.

We agree that electrolyte control normally works in ICU patients, and heart failure is a rare adverse reaction, with a probability of $0.07 \%$ (2). Nevertheless, we would like to draw attention to electrolyte imbalance as an important adverse reaction, so that it is not overlooked.

DOI: $10.3238 /$ arztebl.2019.0115b

\section{References}

1. Fritzenwanker M, Imirzalioglu C, Herold S, Wagenlehner FM, Zimmer KP, ChakrabortyT: Treatment options for carbapenem-resistant gram-negative infections Dtsch Arztebl Int 2018; 115: 345-52.

2. Grabein B, Graninger W, Rodri guez Ban o J, Dinh A, Liesenfeld DB: Intravenous fosfomycin - back to the future. Systematic review and meta-analysis of the clinical literature. Clin Microbiol Infect 2017; 23: 363-72.

On behalf of the authors

Prof. Dr. rer. nat. Trinad Chakraborty

Zentrum für medizinische Mikrobiologie

Koordinator DZIF Gießen-Marburg-Langen, Germany

trinad.chakraborty@mikrobio.med.uni-giessen.de

Conflict of interest statement

The author declares that no conflict of interest exists. 